\title{
The implications of empirical and 1:1 substitution ratios for consequential LCA: using a $1 \%$ tax on whole milk as an illustrative example
}

\author{
Neil George Chalmers ${ }^{1}$ - Matthew Brander ${ }^{2}$. Cesar Revoredo-Giha ${ }^{3}$
}

Received: 2 March 2015 / Accepted: 15 July 2015 / Published online: 4 August 2015

(C) The Author(s) 2015. This article is published with open access at Springerlink.com

\begin{abstract}
Purpose There is an apparent convention within both consequential and attributional life cycle assessment (LCA) to assume a 1:1 substitution ratio between functionally equivalent product systems. However, this convention may not be compatible with the purpose of consequential LCA, which is to model the actual consequences of the decision at hand. This paper explores the implications of the convention using the illustrative example of a $1 \%$ tax on whole milk.

Methods A consequential LCA which assumes a 1:1 substitution ratio between two functionally equivalent product systems is compared with the results of an analysis that estimates the actual substitution ratio based on empirical data. Crossprice elasticities of demand for possible competitor products are modelled using a linear approximated almost ideal demand system (LA-AIDS).

Results and discussion The results show a 1:0.52 substitution ratio between whole and low fat milk, rather than a 1:1 substitution ratio. Depending on the consequential LCA values for whole and low fat milk, the 1:1 convention could underestimate the greenhouse gas emission reductions from the tax by over $400 \%$.
\end{abstract}

Responsible editor: Thomas Swarr

Neil George Chalmers

n.g.chalmers@sms.ed.ac.uk

1 School of GeoSciences, University of Edinburgh, Peter Wilson Building, Edinburgh EH9 3FH, UK

2 University of Edinburgh Business School, 29 Buccleuch Place, Edinburgh EH8 9JS, UK

3 Land Economy, Environment \& Society, Scotland's Rural College (SRUC), West Mains Road, Edinburgh EH9 3FH, UK
Conclusions The results suggest that it is highly important to model actual substitution ratios between competing product systems in order to capture the consequences of the decision at hand. As a subsidiary contribution, the paper also shows the importance of modelling the displacement effects of milk fat co-products, which are generally not considered in the existing LCA literature on milk.

Keywords Consequential life cycle assessment · Demand modelling $\cdot$ Milk products $\cdot$ Substitution ratios

\section{Introduction}

Life cycle assessment (LCA) is an impact assessment tool for "supporting decisions on the substitution between two product systems" (Weidema et al. 2009, p.6), and generally, two distinct types of LCA are identified: attributional LCA (ALCA) and consequential LCA (CLCA). ALCA aims to model the environmental impacts produced by the processes used in the life cycle of the product studied (Ekvall and Weidema 2004; Earles and Halog 2011). In contrast, CLCA aims to model the system-wide change in environmental impacts caused by a change in production volumes or product configuration (Ekvall 2002; Ekvall and Weidema 2004; Curran et al. 2005; Finnveden et al. 2009; Plevin et al. 2014). The development and use of CLCA is largely motivated by the principle that in order to make rational decisions, information is required on the consequences of the decision at hand (Weidema 1993; Ekvall 1999; Wenzel 1998; Plevin et al. 2014). Nevertheless, because CLCA has evolved out of ALCA, there are still a number of methodological features that remain in common, such as the assumption of a 1:1 substitution ratio between the two product systems being compared. 
Plevin et al. (2014) argue that the assumption of a 1:1 substitution ratio is a feature of attributional LCA (though the recent development of advanced ALCA (AALCA) means this may not always be the case (Andrae 2015)) and that CLCA should model the actual rate of substitution that occurs. However, much of the existing guidance for CLCA adheres to the principle of functional equivalence between the two product systems in question, to ensure that the comparison is on a like-for-like basis (Weidema 2003; ISO 2006; European Commission et al. 2010). Similarly, there are many examples of CLCA studies that adhere to a 1:1 substitution ratio, for example, Ekvall and Andræ (2006) calculate the change in emissions achieved by the ban on the use of lead in solder by subtracting the LCA result for lead-based solder from the LCA result for a functionally equivalent quantity of leadfree solder. Even in CLCA studies that explicitly consider the price difference between competing production systems, such as Thiesen et al. (2008), the 1:1 substitution assumption is still present.

There are a number of studies that depart from this convention and model non 1:1 substitution ratios between competing products, particularly in the literature on biofuel policy (Smeets et al. 2014; Rajagopal 2013; Drabik and De Gorter 2011; Taheripour and Tyner 2013; Hochman and Rajagopal 2010). For example, Smeets et al. (2014) use a computational general equilibrium model to estimate a range of substitution ratios between 0.78 and 0.66 (i.e. for every one unit of biofuel produced, between 0.78 to 0.66 units of fossil fuel is substituted). These non 1:1 substitution ratios occur because the supply of biofuels reduces the price of oil, which in turn increases demand for oil elsewhere in the world. In addition, the increased production of biofuels increases GDP in supplying regions, which in turn increases demand for oil. Such studies use partial equilibrium (PE) or general equilibrium (GE) models, and it is precisely because these models tend not adhere to the assumption of functional equivalence that some authors suggest there is a distinction between traditional "biophysical" CLCA and CLCA based on equilibrium modelling (see for example Brandão et al. 2014, p.462). However, this distinction does not appear to be entirely clear-cut as there are examples of CLCA studies that use partial equilibrium modelling but also adhere to a 1:1 substitution ratio, e.g. Ekvall (2000) and Ekvall and Andræ (2006).

Given this background context, the goal of the present study is to further explore the importance of modelling the actual substitution ratio between competing product systems and the implications for CLCA guidance and practice. This is done using the illustrative example of a hypothetical tax on whole milk. The impact category considered is global warming potential, though the implications of the study are equally relevant to other impact categories.

A tax on whole milk was selected as milk is a major food commodity (Cederberg and Stadig 2003) and has received a correspondingly high level of attention in the LCA literature. Cederberg and Stadig (2003) provide an LCA of milk production and explore alternative methods for dealing with beef coproducts from the dairy system. They suggest that "prospective" LCA studies (what would now normally be described as consequential LCA) should use the method of "substitution" when dealing with co-products, as this method provides information on "the environmental consequences of manipulating product systems" (Cederberg and Stadig 2003, p.350). Substitution involves identifying the product systems that are displaced by the co-products and crediting the displacement of those product systems to the decision studied, as the avoidance of those systems and their associated impacts are a consequence of the decision (Ekvall and Weidema 2004; Brander and Wylie 2011).

Thomassen et al. (2008) report the results from both an attributional and a consequential LCA for fat and proteincorrected milk. They also demonstrate the way in which the consequential approach aims to capture the system-wide effects of milk production by including the substitution effects of beef co-products from the dairy sector on dedicated beef and pork production. A similar study is provided by Flysjö et al. (2011), which models six alternative approaches for dealing with beef co-products from milk production, including substitution effects. Dalgaard et al. (2014) present a model for calculating the carbon footprint of energy corrected milk, with a fat content of $4.1 \%$. The consequential modelling option includes the substitution effects of both beef and manure co-products from the dairy system.

One co-product from the dairy system that is generally absent from the existing LCA literature is milk fat from the manufacture of low fat milk. This appears to be because existing studies tend not to differentiate between types of milk with different levels of fat or have selected whole milk as the functional unit, and therefore, milk fat co-products do not arise. In the case of Hospido et al. (2003), milk fat is identified as a co-product but is omitted from the analysis due to its small proportion of total production $(>2.5 \%)$.

One study that does consider milk fat in more depth is Flysjö (2012), where it is argued that skimmed milk and cream (i.e. milk fat) are both "determining" co-products, i.e. an increase in demand for either product will increase the production of both, and in such situations, the treatment of coproducts in consequential LCA will be equivalent to allocation by economic value (Weidema et al. 2009). However, it is plausible that milk fat is not a co-determining product as alternative products exist, at least for some of the applications of milk fat (Ong and Goh 2002), and therefore, the long-run marginal production costs of the alternative products will constrain the price of milk fat and its contribution to the revenue from the co-producing unit process (Weidema et al. 2009). Although the primary contribution of the present article is concerned with the assumption of a 1:1 product substitution 
ratio in CLCA, a subsidiary contribution is an investigation of the displacement effects of milk fat co-products, which is generally absent from the existing literature on milk.

\section{Methodology}

\subsection{Consequential LCA}

The goal of this study is to illustrate the importance of modelling the actual substitution ratio between competing product systems. To this end, the study provides a comparison between a consequential analysis that assumes a 1:1 substitution ratio between two functionally equivalent product systems (the "traditional" LCA approach) and the results of an analysis that estimates the actual substitution ratio based on empirical data. The illustrative decision scenario selected for this purpose is a $1 \%$ tax on whole milk (i.e. the decision-maker is a government appraising the climate change mitigation potential of shifting consumption from whole to low fat milk through the introduction of a $1 \%$ tax on whole milk). This decision scenario was selected for a number of reasons: sufficient data were available from the Kantar Worldpanel dataset for modelling the price elasticities of demand for different milk products; a tax on whole milk is an example of a realworld policy option, albeit one that has proved difficult to implement (BBC 2012); and, as mentioned, there is a wealth of LCA studies on milk, and the topic has played something of a test case for methodological debate within the literature (Cederberg and Stadig 2003; Thomassen et al. 2008; Flysjö et al. 2011; Dalgaard et al. 2014).

The decision to implement a $1 \%$ tax on whole milk implies a switch from whole milk to an alternative product, such as low fat milk. For either of the substitution ratio approaches identified (i.e. the assumption of a 1:1 ratio or an empirical ratio), in order to model the change in greenhouse gas emissions, it is necessary to quantify the emissions from the alternative product systems. In the case of whole milk and low fat milk, the only difference is the quantity of milk fat co-products supplied, as all raw milk is initially skimmed to produce skimmed milk and cream, and in order to produce whole or low fat milk, some of the cream is re-added (Stephens 2014, personal communication., 25 July) This entails that there is almost no difference in the upstream processing of the products, other than the blending process for re-introducing milk fat to produce higher fat content milk products (i.e. low fat milk does not require a skimming process that is absent for whole milk). Standardised whole milk has a minimum fat content of $3.5 \%$, and for the present study, it is assumed that whole milk has an average fat content of $4 \%$, and low fat milk has a fat content of $1 \%$.

The focus of this study is CLCA, and therefore, substitution was used to estimate the greenhouse gas effects from different amounts of milk fat co-product produced. Palm oil was identified as the marginal product that is likely to be substituted by an increase in the supply of milk fat as it is readily substitutable for milk fat in food products (Ong and Goh 2002), and it is identified as the world marginal vegetable oil product (Schmidt and Weidema 2008). In reality, there may be a mix of marginal products that are affected by an increase in the supply of any given substitute product (Ekvall and Andræ 2006; Mathiesen et al. 2009); however, the simplified assumption that palm oil is substituted is sufficient for the illustrative purposes of the present study. Figure 1 provides an overview of the changes that are modelled.

It was not possible to find data for the substitution ratio between milk fat and palm oil, and therefore, a 1:1 mass ratio was assumed, though the actual ratio is likely to vary by application, based on taste, texture, price, and other technical considerations. As above, this simplified assumption is sufficient for the illustrative purposes of this study. A range of LCA results for palm oil were sourced from Schmidt (2010) and Brinkmann Consultancy (2009), in order to explore the sensitivity of the results to different estimates for the emissions from the substituted product. The emissions avoided by the substitution of palm oil were subtracted from a published CLCA figure for whole milk $\left(901 \mathrm{gCO}_{2} \mathrm{e} / \mathrm{kg}\right.$ from Thomassen et al. (2008), which was converted to $\mathrm{gCO}_{2} \mathrm{e} / \mathrm{L}$ using a density factor of $1.035 \mathrm{~kg} / \mathrm{L}$ of whole milk), to estimate the consequential results for low fat milk.

\subsection{Demand modelling}

The effect of a $1 \%$ tax on whole milk was modelled using Scottish household purchasing data obtained from Kantar Worldpanel datasets for the years 2006-2011 (i.e. time series data). The dataset is comprised of five milk products: low fat, semi-skimmed, skimmed, soy, and whole.

Own price elasticity of demand measures the responsiveness of a change in quantity demanded of product A (e.g. whole milk) to a change in the price of product A (Snyder and Nicholson 2008). Cross-price elasticity is how the quantity demanded of product B ( e.g. low fat milk) responds to a change in the price of product A (e.g. whole milk), and income elasticities are similar to price elasticities yet measure the responsiveness of a change in quantity demanded to a change in income. In the present study, Marshallian elasticities (which account for both income and substitution effects) are modelled from the data to show how a $1 \%$ price increase in whole milk would likely affect the demand for whole milk (i.e. own price elasticity), as well as the demand for substitute goods (i.e. cross-price elasticity).

The Marshallian elasticities were modelled using a linear approximated almost ideal demand system (LA-AIDS). The LA-AIDS system was first developed by Deaton and Muellbauer (1980a) and has the advantage over the previously 


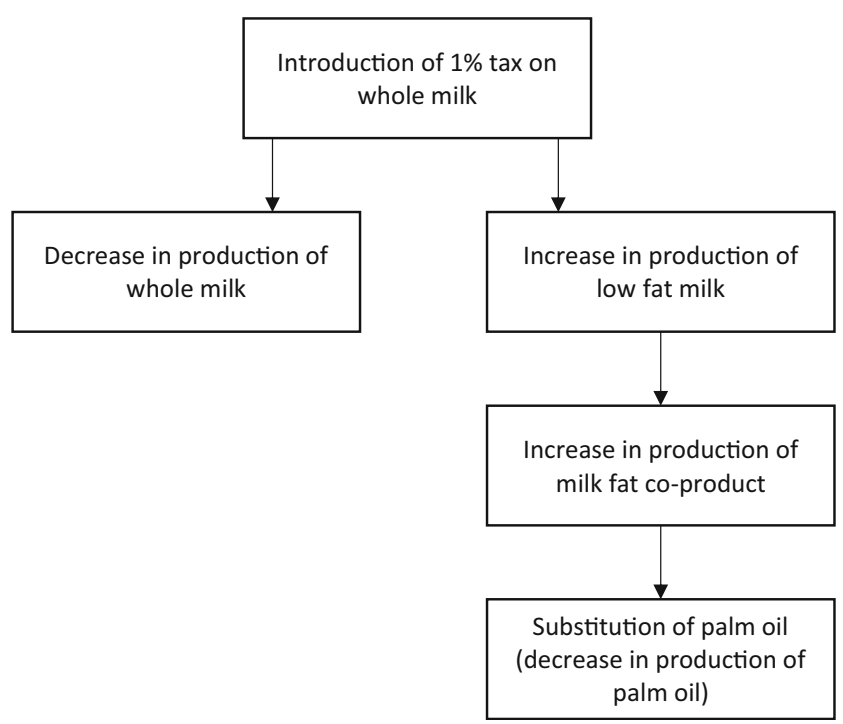

Fig. 1 Flow diagram of the decision model

common Rotterdam or Translog demand models whereby the AIDS can impose linear demand theory restrictions and can calculate arbitrary first order approximations for a given demand system (i.e. set of equations). The consumer derives utility from quantities of goods/services, yet when faced with a linear budget constraint, the utility function is dependent upon expenditure and prices, i.e. the indirect utility function (Deaton and Muellbauer 1980b). This highlights the relationship between utility and the demand function. The demand function is incorporated into the demand system. This study builds on the model presented in Chalmers et al. (2014), as low fat milk is incorporated into the LA-AIDS for the whole of Scotland.

A further benefit of the LA-AIDS is the ability to be consistent with the theory of a consumer maximising his/her preferences subject to a budget constraint (Deaton and Muellbauer 1980b). Consumer demand modelling involves meeting the various economic demand theory rules (Deaton and Muellbauer 1980b) which makes it more complex than directly calculating the demand elasticities, as in Ekvall and Weidema (2004). The LA-AIDS model has featured in studies relating to price elasticities of food products (Tiffin and Tiffin 1999). A more recent application modelled Kenyan household demand for different energy products (e.g. kerosene) through the use of a conditional LA-AIDS (Ngui et al. 2011). In the present paper, the conditional LA-AIDS model only considers expenditure on milk products.

$$
\begin{aligned}
& w_{i t}= \alpha_{i}+\beta_{i} \ln \left(\frac{m_{t}}{P_{t}^{*}}\right)+\sum_{j=1}^{N} \gamma_{i j} \ln \left(p_{j t}\right) \\
&+\sum_{k=1}^{K} \beta_{i k} D_{k t}+T+u_{i t} \\
& \ln \left(P_{t}^{*}\right)=\sum_{j=1}^{N} w_{j t} \ln \left(p_{j t}\right)
\end{aligned}
$$

The LA-AIDS model is shown by Eq. (1) and is linear due to the price index of Eq. (2). The LA-AIDS has the following four restrictions of demand theory imposed (Deaton and Muellbauer 1980b): adding up, homogeneity, symmetry, and negativity. ${ }^{1}$ Homogeneity and symmetry restrictions can be directly imposed on the LA-AIDS model while negativity can be inferred from the elasticity results. The adding-up restriction is imposed through dropping one of the equations in the estimation of the LA-AIDS (Wan et al. 2010).

The parameters in Eqs. (1) and (2) are $w=$ budget shares, $m=$ expenditure, $P_{\mathrm{t}}=$ price index, $\gamma=$ relative prices, and $D=$ seasonal dummy variables with subscript $k$ representing 12 dummy variables as there are 13 periods within each year (this avoids the problem of the dummy variable trap), and a time trend is also included ( $T$ ). Subscripts $t=$ time; $i$ and $j$ represent dairy products. The expenditure allocated to milk products by households is assumed to be fixed as this is a conditional demand system model. The LA-AIDS model used in this study is calculated in R, using package "Erer" (Sun 2014) which is based on Wan et al. (2010).

The Marshallian elasticities were applied to volume data for individual milk products (Table 1), in order to calculate the change in consumption resulting from a hypothetical $1 \%$ tax on whole milk. Milk purchasing volumes were obtained from DairyCo (2014) which in turn were supplied from Kantar Worldpanel for the 52-week period ending on the 12th of October 2014. The dataset covered the whole of the UK and was adjusted to account for Scottish purchasing using Defra's 2013 household consumption dataset (Defra 2014), which is the most recent consumer purchasing data available. The limitation of this adjustment method is that Defra aggregated both liquid milk and cream into one group, though no other method could be devised to create a representative dataset. The Kantar dataset used in the demand model has not been used in the volume calculations as the DairyCo supplied Kantar data are more recent. Therefore, this allows for an idea of the potential impact of a $1 \%$ tax on quantity demanded of the differing milk products.

\section{Results}

The condition of negativity is met since all the own price elasticities are negative and statistically significant. Table 2 shows the Marshallian cross-price elasticities of the different milk products with regard to a change in the price of whole milk. The results suggest that a $1 \%$ tax on whole milk is likely to decrease demand for whole milk by $1.48 \%$ and increase demand for low fat milk by $3.44 \%$. The elasticities for the

\footnotetext{
$\overline{{ }^{1} \text { This matrix C }}$ must be negative semi-definite for the restriction of negativity to apply (Deaton and Muellbauer 1980b).
} 
Table 1 Total purchases of milk

\begin{tabular}{ll}
\hline Products & $\begin{array}{l}\text { 52-week period (ending 12 Oct. 2014) } \\
\text { Quantity (million litres) }\end{array}$ \\
\hline Low fat & 57.15 \\
Semi-skimmed & 713.16 \\
Skimmed & 158.94 \\
Soya milk & 31.98 \\
Whole milk & 255.44 \\
Total & 1216.67 \\
\hline
\end{tabular}

other alternative milk products are not statistically significant and are not used in the remainder of the analysis.

Table 3 shows the CLCA results for low fat and whole milk, with a credit given to the avoided emissions from the milk fat co-product from the low fat milk. The highest estimate of palm oil emissions (36.15 $\mathrm{tCO}_{2} \mathrm{e} /$ tonne of palm oil) gives in a net negative result ( $-190 \mathrm{gCO}_{2} \mathrm{e} / \mathrm{L}$ of low fat milk), as the avoided palm oil emissions are greater than the rest of the life cycle emissions for low fat milk. The high estimate of palm oil emissions is due to deforestation and peatland drainage associated with palm cultivation. Depending on the size of the credit given for avoided palm oil production, the difference between the CLCA emissions for low fat and whole milk varies between a $10 \%$ difference and a $120 \%$ difference.

Table 4 shows the estimated change in consumption caused by a $1 \%$ tax on whole milk in litres (derived from the volume data in Table 4 and the elasticities for low fat and whole milk in Table 2). Whole milk consumption decreases by a greater quantity than the increase in low fat milk consumption, indicating that there will be an overall decrease in the total amount of milk consumed.

Table 5 provides a comparison of the two different approaches to the substitution ratio between whole milk and low fat milk. The empirical substitution ratio is 0.52 (derived by dividing the change in low fat milk consumption by the change in whole milk consumption), i.e. for every $1 \mathrm{~L}$ reduction in whole milk consumption an additional $0.52 \mathrm{~L}$ of low fat milk is consumed. The estimated effects of the $1 \%$ tax based on the 1:1 ratio approach and empirical ratio approach differ greatly, depending on the change in emissions caused by

Table 2 Marshallian elasticities

\begin{tabular}{lll}
\hline & Whole milk (\%) & Statistical significance \\
\hline Low fat & 3.445 & $* * *$ \\
Semi-skimmed & 0.159 & \\
Skimmed & -1.035 & \\
Soya & -0.581 & \\
Whole & -1.483 & $* *$ \\
\hline
\end{tabular}

Statistical significance: *10\%;**5\%;***1\% the production of low fat milk. In the extreme case, the 1:1 ratio may underestimate the reduction in emissions caused by the tax by $416 \%$.

\section{Discussion}

As with any assessment of system-wide consequences, there are numerous sources of uncertainty with the estimated effects of the decision (Plevin et al. 2014). Some of these are indicated in the analysis of the tax on whole milk, e.g. by the magnitude of difference between the results from different parameter values for the emissions associated with palm oil (Table 5). One source of uncertainty that is worth highlighting, as it could be considerable, is the possibility of other consequences from the $1 \%$ tax (which are not included in the model). The additional tax revenue could allow the government to reduce taxes elsewhere in the economy, causing an increase in demand in the affected markets, with associated increases in emissions (however, further econometric modelling would be required in order to support this claim). Alternatively, the government could spend the additional tax revenue itself, either increasing or decreasing environmental impacts, depending on whether the expenditure is on environmental protection measures or other items.

The main limitation of the conditional demand model (an almost ideal demand system) is the modelling of only milk products. The model's assumption is that milk expenditures are fixed and thus remain constant during the modelled time period. Klonaris and Hallam (2003) have criticised this form of demand modelling and emphasised the need for converting to unconditional demand models. However, unconditional demand models require more data as they model the various food groups, and the problem of group expenditure being treated as exogenous in the model may still exist (Thompson 2004). The potential of using the conditional model with endogenous group expenditure could result in the violation of demand theory (Thompson 2004). Therefore, this paper accepts that there are limitations and benefits to using the conditional almost ideal demand system.

Despite these limitations, if the goal of a CLCA is to model the actual consequences from the decision at hand then modelling the actual substitution ratio does appear highly important. To add further illustrative detail to the milk example and assuming the Schmidt (2010) figure for palm oil, if a policymaker were given the 1:1 emissions reduction estimate of $97 \mathrm{gCO}_{2} \mathrm{e} / \mathrm{L}$ of milk substituted, then he/she may decide not to proceed with the tax. In contrast, the actual reduction may be over four times greater than the 1:1 estimate, and an effective mitigation opportunity would be missed. Adherence to a 1:1 substitution ratio may undermine the aim of estimating the actual consequences of the decision at hand. 
Table 3 Consequential LCA results with substitution for milk fat co-products

\begin{tabular}{llllll}
\hline & $\begin{array}{l}\text { Milk fat } \\
\text { Co-product }(\mathrm{g} / \mathrm{L})\end{array}$ & Schmidt 2010 & $\begin{array}{l}\text { Brinkmann 2009 } \\
\text { (Lower estimate) }\end{array}$ & $\begin{array}{l}\text { Brinkmann 2009 } \\
\text { (Upper estimate) }\end{array}$ \\
\hline $\begin{array}{l}\text { Consequential LCA result_low fat milk } \\
\begin{array}{l}\text { Consequential LCA result_whole milk } \\
\text { \% difference between products }\end{array}\end{array}$ & 0 & 81 & 831 & -190 & 933 \\
\hline
\end{tabular}

However, there are at least three possible responses from adherents to the $1: 1$ ratio convention:

1. It is questionable whether empirically derived substitution ratios $d o$ actually provide a more accurate representation of reality than 1:1 ratios. One short-coming with empirical elasticities is that they tend to be short-run elasticities, as these are easier to measure (Weidema et al. 2009), whereas environmental assessment is normally concerned with the long-term effects from decisions. Theoretically, elasticities of demand and supply are expected to be more elastic in the long run, as consumers and producers will have more opportunities for adjusting to the change in price (Ekvall 2000, p.97), and therefore, short-run empirical elasticities may not accurately model what happens in the long run.

However, the relative accuracy of 1:1 versus empirical substitution ratios appears to be, with some irony, itself an empirical question (rather than one of principle), and further empirical research is needed to determine whether the 1:1 assumption is a reasonable approximation of long-run substitution or not. The empirical findings from the present study, which does model long-run elasticities given the time period 2006 to 2011, and those in the biofuel domain (e.g. Smeets et al. (2014)), indicate that rates of substitution may be very different from 1:1.

In addition, many CLCA studies that adhere to the 1:1 convention also use elasticities to model other marketmediated consequences, such as changes in the demand for inputs or the supply of outputs (e.g. Ekvall (2000); Ekvall and Andræ (2006)), and if elasticities are sufficiently representative for those purposes, they should also be sufficiently representative for modelling substitution ratios.

2. A second response is to suggest that the 1:1 ratio approach is actually capable of modelling the consequences captured by the empirical ratio approach, and so, there is no

Table 4 Change in consumption (million litres)

\begin{tabular}{lc}
\hline Products & Change (million litres) \\
\hline Low fat milk & 1.97 \\
Whole milk & -3.79 \\
Total & -1.82
\end{tabular}

loss of information from maintaining the convention. For example, Thiesen et al. (2008) assume a 1:1 substitution ratio and model the indirect rebound effects of price differences between two cheese products by including the environmental impacts from the increased consumption which is caused by saving money on the lower cost cheese (indirect rebound effects occur when changes in the effective cost of one product causes changes in the consumption of other products (Freire-González 2011)). There may be a similar way of formulating the functional units of the milk products to include the price differences and thereby maintain 1:1 functional equivalence.

However, a simpler and more parsimonious account is that the $1 \%$ tax reduces the demand for whole milk, and the demand for low fat milk does not increase by the same amount. There may be a way of formulating the functional units to maintain 1:1 functional equivalence, but it is not immediately obvious what the explanatory, conceptual or, methodological benefits would be.

Table 5 Comparison of different approaches to the product substitution ratio

\begin{tabular}{|c|c|c|c|c|c|}
\hline & \multirow[b]{2}{*}{$\begin{array}{l}\text { Substitution } \\
\text { ratio (litre } \\
\text { of low fat } \\
\text { milk } 1 \mathrm{~L} \text { of } \\
\text { whole milk) }\end{array}$} & \multicolumn{3}{|c|}{$\begin{array}{l}\text { Reduction in emissions from } \\
1 \% \text { tax on whole milk }\end{array}$} & \\
\hline & & $\begin{array}{l}\text { Schmidt } \\
2010\end{array}$ & $\begin{array}{l}\text { Brinkman } \\
2009 \\
\text { (lower } \\
\text { estimate) }\end{array}$ & $\begin{array}{l}\text { Brinkman } \\
2009 \\
\text { (upper } \\
\text { estimate) }\end{array}$ & \\
\hline $\begin{array}{l}1: 1 \\
\quad \text { substitution } \\
\quad \text { ratio }\end{array}$ & 1 & 97 & 101 & 1122 & $\begin{array}{l}\mathrm{gCO}_{2} \mathrm{e} / \\
\mathrm{L} \text { of } \\
\text { whole } \\
\text { milk } \\
\text { re- } \\
\text { duced }\end{array}$ \\
\hline $\begin{array}{l}\text { Empirical } \\
\text { substitution } \\
\text { ratio }\end{array}$ & 0.52 & 498 & 501 & 1031 & $\begin{array}{l}\mathrm{gCO}_{2} \mathrm{e} / \\
\mathrm{L} \text { of } \\
\text { whole } \\
\text { milk } \\
\text { re- } \\
\text { duced }\end{array}$ \\
\hline $\begin{array}{c}\% \text { difference } \\
\text { between } \\
\text { approaches }\end{array}$ & $-48 \%$ & $416 \%$ & $394 \%$ & $-8.1 \%$ & \\
\hline
\end{tabular}


3. The third response is to identify two separate forms of CLCA (as per Brandão et al. (2014)): "biophysical" CLCA which maintains 1:1 substitution ratios and a form of CLCA which does not.

However, as noted above, elasticities are used for modelling other consequences within CLCA, such as the effect of changes in demand for inputs or changes in the supply of co-product outputs. It appears to be an arbitrary proscription that elasticities should not also be used to model product substitution ratios. In addition, the suggested distinction cannot be based on the use of partial or general equilibrium modelling as there are instances of $\mathrm{PE}$ modelling that adhere to the $1: 1$ assumption, and there are also instances of CLCA, such as the present paper, which do not use PE or GE but do depart from using a 1:1 substitution ratio.

A slightly different argument in favour of empirical elasticities is that they are highly useful for identifying the comparator product, as well as the substitution ratio. The crossprice elasticities for skimmed, semi-skimmed, and soya milk were not statistically significant, which suggests that these products would not be affected by the tax on whole milk, and these products can therefore be excluded from the analysis of comparator systems. An alternative method for identifying the comparator product involves a three-step procedure for identifying obligatory and positioning properties, market segments, and the products within those market segments with the identified properties (Weidema et al. 1999; Ekvall and Weidema 2004). The use of empirical data to model the cross-price elasticity offers a more objective assessment of what the substitute product(s) will be.

A final point on the use of empirical substitution ratios is the importance of modelling the specific decision in question or type of intervention used to implement the change. An apparent assumption under-pinning the 1:1 ratio convention is that the decision in question is always a straightforward choice between two functionally equivalent products, whereas in reality, this is an oversimplification (as illustrated by the example of the tax). In the case of the regulation banning lead-based solder (Ekvall and Andræ 2006), the choice of a 1:1 substitution ratio may be a reasonable estimate, as the intervention itself does not involve the manipulation of price, in contrast to a tax, although there could still be a change in price and a reduction in total demand for solder, if lead-free solder has higher cost than lead-based solder. The different substitution effects from different types of intervention, such as taxes, regulations, and information campaigns, could be investigated in future research.

In terms of the subsidiary purpose of this paper, i.e. to contribute to the LCA literature on milk, a clear finding is that milk with different levels of fat content is likely to have very different greenhouse gas emissions consequences. In the extreme case, the additional production of low fat milk may create a net reduction in emissions, due to the substitution of palm oil. These effects have not previously been explored in the LCA literature.

\section{Conclusions}

A guiding principle of CLCA is that it should model the actual consequences of the decision at hand; however, the convention of assuming a 1:1 substitution ratio between comparator products does not necessarily adhere to this principle. This paper provides evidence to suggest that CLCA should model empirical substitution ratios as these may differ significantly from the 1:1 assumption. In the case of the ratio between whole milk and low fat milk, this was found to be 0.52 and not 1 as convention would suggest. The 1:1 assumption could lead to a large underestimation in the emission reductions caused by a $1 \%$ tax on whole milk.

Based on the analysis presented above, it is recommended that existing guidance and standards, such as ISO 14044 and the ILCD Handbook are amended to allow the use of alternative substitution ratios and that the assumption of a 1:1 ratio should be viewed as a heuristic or default value in the absence of other information, rather than as a methodological principle.

Allowing the use of non 1:1 substitution ratios between competing products is a departure from what may be described as "biophysical" CLCA but appears to be wholly consistent with the aim of modelling the actual consequences of the decision at hand.

Acknowledgments Neil Chalmers would like to acknowledge Scotland's Rural College (SRUC) and the Scottish Government's Rural and Environment Science and Analytical Services Division (RESAS) under Theme 4.2 of the "Developing a Low Carbon Rural Economy" Programme (2011-2016), for their financial support.

Matthew Brander would like to acknowledge the UK's Economic and Social Research Council (ESRC), in partnership with the Society for the Advancement of Management Studies (SAMS) and the UK Commission for Employment and Skills (UKCES), for their support through the Management and Business Development Fellowship Scheme.

The authors would like to thank the two anonymous reviewers for their extremely helpful comments and suggestions for improving the article.

\section{Compliance with ethical standards}

Conflicts of interest The authors declare that they have no competing interests.

Open Access This article is distributed under the terms of the Creative Commons Attribution 4.0 International License (http:// creativecommons.org/licenses/by/4.0/), which permits unrestricted use, distribution, and reproduction in any medium, provided you give 
appropriate credit to the original author(s) and the source, provide a link to the Creative Commons license, and indicate if changes were made.

\section{References}

Andrae ASG (2015) Method based on market changes for improvement of comparative attributional life cycle assessments. Int J Life Cycle Assess 20(2):263-275

BBC (2012) Denmark to abolish tax on high-fat foods., Available at: http://www.bbc.co.uk/news/world-europe-20280863 [Accessed January 23, 2015]

Brandão M et al (2014) The use of life cycle assessment in the support of robust (climate) policy making: comment on "using attributional life cycle assessment to estimate climate-change mitigation". J Ind Ecol 18(3):461-463

Brander M, Wylie C (2011) The use of substitution in attributional life cycle assessment. GHG Measure Manage 1(3-4):161-166

Brinkmann Consultancy (2009) Greenhouse gas emissions from palm oil production-literature review and proposals from the RSPO Working Group on Greenhouse Gases, Hoevelaken., Available at: http://www.rspo.org/files/project/GreenHouse.Gas. Working.Group/ Report-GHG-October2009.pdf [Accessed February 25, 2015]

Cederberg C, Stadig M (2003) System expansion and allocation in life cycle assessment of milk and beef production. Int J Life Cycle Assess 8(6):350-356

Chalmers NG, Revoredo-Giha C, Shackley SJ (2014) How prices affect Scottish household demand for milk products and their low carbon alternatives? EAAE 2014 congress., Available at: http://purl.umn. edu/182965 [Accessed June 24, 2015]

Curran MA, Mann M, Norris G (2005) The international workshop on electricity data for life cycle inventories. J Clean Prod 13(8):853862

DairyCo (2014) Dairy sales and consumption., Available:http://www. dairyco.org.uk/resources-library/market-information/dairy-salesconsumption/?page $=1 \#$.VNC4TWisXT8 [Accessed on February 3, 2015]

Dalgaard R, Schmidt J, Flysjö A (2014) Generic model for calculating carbon footprint of milk using four different life cycle assessment modelling approaches. J Clean Prod 73:146-153

Deaton A, Muellbauer J (1980a) An almost ideal demand system. Am Econ Rev 70(3):312-326

Deaton A, Muellbauer J (1980b) Economics and consumer behavior. Cambridge University Press, Cambridge, UK

Defra (2014) Family food 2013., Available at: https://www.gov.uk/ government/uploads/system/uploads/attachment data/file/385694/ familyfood-2013report-11dec14.pdf [Accessed February 15, 2015]

Drabik D, De Gorter H (2011) Biofuel policies and carbon leakage. AgBioForum 14(3):104-110

Earles JM, Halog A (2011) Consequential life cycle assessment: a review. Int J Life Cycle Assess 16(5):445-453

Ekvall T (1999) Key methodological issues for life cycle inventory analysis of paper recycling. J Clean Prod 7(4):281-294

Ekvall T (2000) A market-based approach to allocation at open-loop recycling. Resour Conserv Recy 29:91-109

Ekvall T (2002) Cleaner production tools: LCA and beyond. J Clean Prod 10:403-406

Ekvall T, Andræ ASG (2006) Attributional and consequential environmental assessment of the shift to lead-free solders. Int J Life Cycle Assess 11(5):344-353

Ekvall T, Weidema B (2004) System boundaries and input data in consequential life cycle inventory analysis. Int J Life Cycle Assess 9(3): $161-171$
European Commission, Joint Research Centre \& Institute for Environment and Sustainability (2010) International reference life cycle data system handbook. European Commission, Luxembourg

Finnveden $\mathrm{G}$ et al (2009) Recent developments in life cycle assessment. J Environ Manage 91(1):1-21

Flysjö A (2012) Greenhouse gas emissions in milk and dairy product chains - improving the carbon footprint of dairy products. Aarhus University., Available at: http://pure.au.dk/portal/files/45485022/ anna_20flusj_.pdf. [Accessed February 22, 2015]

Flysjö A et al (2011) How does co-product handling affect the carbon footprint of milk? Case study of milk production in New Zealand and Sweden. Int J Life Cycle Assess 16(5):420-430

Freire-González J (2011) Methods to empirically estimate direct and indirect rebound effect of energy-saving technological changes in households. Ecol Model 223(1):32-40

Hochman G, Rajagopal D (2010) The effect of biofuels on crude oil markets. AgBioForum 13(2):112-118

Hospido A, Moreira MT, Feijoo G (2003) Simplified life cycle assessment of galician milk production. Int Dairy J 13(10):783-796

ISO (2006) ISO 14044: 2006 —Environmental management—life cycle assessment-requirements and guidelines. International Organization for Standardization, Geneva, Switzerland

Klonaris S, Hallam D (2003) Conditional and unconditional food demand elasticities in a dynamic multistage demand system. Appl Econ 35(5):503-514

Mathiesen BV, Münster M, Fruergaar T (2009) Uncertainties related to the identification of the marginal energy technology in consequential life cycle assessments. J Clean Prod 17(15):1331-1338

Ngui D et al (2011) Household energy demand in Kenya: an application of the linear approximate almost ideal demand system (LA-AIDS). Energ Policy 39(11):7084-7094

Ong ASH, Goh SH (2002) Palm oil: a healthful and cost-effective dietary component. Food Nutr Bull 23(1):11-22

Plevin RJ, Delucchi MA, Creutzig F (2014) Using attributional life cycle assessment to estimate climate-change mitigation benefits misleads policy makers. J Ind Ecol 18(1):73-83

Rajagopal D (2013) The fuel market effects of biofuel policies and implications for regulations based on lifecycle emissions. Environ Res Lett 8(2):024013

Schmidt J (2010) Comparative life cycle assessment of rapeseed oil and palm oil. Int J Life Cycle Assess 15(2):183-197

Schmidt J, Weidema B (2008) Shift in the marginal supply of vegetable oil. Int J Life Cycle Assess 13(3):235-239

Smeets E et al (2014) The impact of the rebound effect of the use of first generation biofuels in the EU on greenhouse gas emissions: a critical review. Renew Sust Energy Rev 38:393-403

Snyder C, Nicholson W (2008) Microeconomic theory. Thomson SouthWestern, Canada

Sun CY (2014) Empirical research in economics with R (Package 'erer')., Available at: $h$ ttp://cran.r-project.org/web/packages/erer/erer.pdf [Accessed February 15, 2014]

Taheripour F, Tyner WE (2013) Induced land use emissions due to first and second generation biofuels and uncertainty in land use emission factors. Economics research international

Thiesen J, Christensen TS, Kristensen TG, Andersen RD, Brunoe B, Gregersen TK, Thrane M, Weidema BP (2008) Rebound effects of price differences. Int J Life Cycle Assess 13(2):104-114

Thomassen MA et al (2008) Attributional and consequential LCA of milk production. Int J Life Cycle Assess 13:339-349

Thompson W (2004) Using elasticities from an almost ideal demand system? Watch out for group expenditure! Am J Agr Econ 86(4): $1108-1116$

Tiffin A, Tiffin R (1999) Estimates of food demand elasticities for Great Britain: 1972-1994. J Agr Econ 50(1):140-147

Wan Y, Sun C, Grebner DL (2010) Analysis of import demand for wooden beds in the U.S. J Agr Appl Econ 42(4):643-658 
Weidema B (1993) Market aspects in product life cycle inventory methodology. J Clean Prod 1(3):161-166

Weidema B (2003) Market information in life cycle assessment. Danish Environmental Protection Agency, Copenhagen, Denmark

Weidema B, Frees N, Nielsen A-M (1999) Marginal production technologies for life cycle inventories. Int $\mathrm{J}$ Life Cycle Assess 4(1):48-56
Weidema B, Ekvall T, Heijungs R (2009) Guidelines for application of deepened and broadened LCA, Rome., Available at: http://www. leidenuniv.nl/cml/ssp/publications/calcas_report_d18.pdf [Accessed February 25, 2014]

Wenzel H (1998) Application dependency of LCA methodology: key variables and their mode of influencing the method. Int $\mathrm{J}$ Life Cycle Assess 3(5):281-288 